Tweeting Morals in the 2016 Election

JP Prims, Zachary J. Melton, \& Matt Motyl

University of Illinois, Chicago

This is the final version of the manuscript that was published as a chapter in Irrational Politics:

The Allure of Donald Trump. Please cite as follows:

Prims, J., Melton, Z. J., \& Motyl, M. (2017). Tweeting morals in the 2016 election. In M. Fitzduff (Ed.), Irrational Politics: The Allure of Donald Trump (pp. 171-189). Praeger. 


\section{Tweeting Morals in the 2016 Election}

Making predictions about which presidential hopeful will win is difficult in the best of times. The 2016 primaries were particularly capricious. In the early days of the primaries few would have predicted that Senator Bernie Sanders would be one of the last two Democrats standing, much less that Donald Trump would secure the Republican nomination (Silver, 2015a; Enten, 2015; Rifkin, 2015). Many predicted that establishment candidates like Hillary Clinton and Jeb Bush would win and that the unconventional candidates like Sanders and Trump would drop out without posing a significant challenge to the establishment candidates (Silver, 2015a, Silver, 2015b; Ostroy, 2015).

Their predictions seemed reasonable at the time, as Donald Trump has never held an elected office, and has little political experience ("Donald Trump Biography", 2016). He is a businessman by trade, and, as a political candidate, he throws out radical ideas and supports radical measures to deal with the nation's most important issues. He is not the only candidate to do so. Senator Bernie Sanders spent much of his career as an outsider who supported some radical policies including universal health care, student loan debt forgiveness, and free college tuition.

However, over the past forty years, Sanders has not wavered in his political beliefs (Keith, 2015; Horowitz, 2016), and nor has Senator Ted Cruz. Sanders has preached the same far left of center message advocating for social and political change without pause, and did not sponsor a single bipartisan bill in 2015 (“Sen. Bernie Sanders”, 2016). Senator Ted Cruz is similar in that he has preached the same conservative message for many years, and sponsored the fewest bipartisan bills of any Senate Republican in 2015 (Flegenheimer, 2016; "Sen. Ted Cruz.", 2016). Accordingly, both senators may be considered ideologues, as they strictly stick with a 
particular ideological agenda and will not compromise on that agenda (Tetlock, 1983). Both are loyal to their ideological values, and are unwilling to compromise with other ideologies, regardless of the issue.

Hillary Clinton cannot be categorized as an ideologue. While she may not be as bipartisan as she claims, $44 \%$ of her resolutions and bills had at least one Republican cosponsor (Emery, 2016). She was not always a "liberal" or "progressive" Democrat. When she was younger she campaigned for Republican presidential nominee Barry Goldwater, but has adopted a more liberal stance on several issues since 2008 (Biography.com, 2016; Riddel, 2015).

Donald Trump is similar to Clinton in that his political beliefs have wavered, he has identified with both the Democratic and Republican parties, and has donated a substantial amount of money to Democrats including Hillary Clinton (Moody, 2016). He changes his position from liberal to conservative and back on a relatively regular basis (Diamond, 2016; Keneally, 2016). His platform is a mixture of liberal and conservative positions ("Donald Trump", 2016). He supports stricter immigration laws and opposes environmental energy reforms, but supports raising taxes on the wealthy and raising the minimum wage. Trump's unexpected popularity may owe itself, in part, to the fact that many voters are not ideologues, and his mix of conservative and liberal positions may be part of his appeal (Sides \& Tesler, 2016). This political malleability may have provided Trump an edge over Senator Ted Cruz, helping him to procure the Republican nomination for the presidency (Steinhauer, 2016). The fact that he is not a strict ideologue allows him to appeal to a broader swath of voters, and it may be that why Trump supporters expect that he will accomplish more than the other candidates: he is willing to say and do whatever he thinks will solve the nation's problems, regardless of party lines (Li, 2016; Ohio Exit Poll, 2016; Florida Exit Poll, 2016; New Hampshire Exit Poll, 2016). 
On many issues Trump has taken extreme positions. His desire to build a wall between the United States and Mexico or to ban all Muslim immigration are dramatic, but they notably did not prevent him from succeeding in the Republican primary, and indeed may have helped him. . While candidates like Sanders and Cruz are consistent ideologues, and Trump is more like Clinton; he is ideologically inconsistent.

Radical proposals often tap into important moral concerns that voters have and may mobilize portions of the electorate who may not ordinarily vote because their traditional electoral options do not represent their core moral priorities. Indeed, past research shows that people who do not vote report more moral priorities that deviate from those of their political party compared to people who do vote (Johnson, Iyer, Wojcik, Vaisey, \& Miles, et al., 2014). This ideological partisan divide seems to be rooted in clashing moral priorities (Hunter, 1992; Sowell, 2007). Indeed, these differences in moral priorities predict policy positions above and beyond demographics, including political ideology (Koleva, Graham, Iyer, Ditto, \& Haidt, 2012).

Moral Foundations Theory (MFT) is a relatively new field of research (Haidt \& Graham 2007). It is a social psychological theory which addresses the variations in human moral priorities across groups and cultures. Much of its work has focused on how moral priorities underlie political conflict in the United States. MFT proposes that there are at least five different foundations of moral beliefs: care/Harm, Fairness/cheating, loyalty/betrayal, Authority/subversion, and Purity/degradation (Graham et. al, 2013) ${ }^{\mathrm{i}}$. The Care/Harm foundation examines the intuition to protect and nurture those who potentially cannot protect themselves. The Fairness/Cheating foundation examines the intuition to have just/fair outcomes, such as e.g. people getting paid equal amounts for equal work. The Loyalty/Betrayal foundation examines the intuition to remain faithful to one's Ingroup and punish those who are disloyal. The 
Authority/Subversion foundation examines the intuition to obey those in some position of power (e.g., military members, parents, police officers, religious leaders). The

Sancity/Purity/Degradation examines the intuition to preserve both bodily and spiritual integrity

- violations of this foundation could be having sex with a dead chicken or defecating on a

religious text. Previous research has suggested that liberals and conservatives place different emphases on different foundations (Graham, Haidt, \& Nosek, 2009). Liberals tend to prioritize Harm/care and Fairness/cheating foundations, while conservatives prioritize all of the foundations approximately equally. In practice this means that conservatives generally prioritize Harm/care and Fairness/cheating less than liberals do, but prioritize loyalty/betrayal, Authority/subversion, and Purity/degradation more than liberals do.

But Democrats and Republicans are not homogeneous parties comprised of individuals who share the exact same moral priorities to the same extent. Different candidates tend to place different emphases on different foundations, and attract different supporters within parties. In a survey of supporters of different candidates Trump supporters prioritized Fairness and loyaltyAuthority-sanctity, and were less concerned about care. Cruz supporters prioritized Fairness above all, and care the least. Sanders supporters prioritized care, and were less concerned about Fairness and loyalty-Authority-sanctity (Ekins \& Haidt, 2016). Clinton supporters emphasized care more than the average American, but were less concerned about Fairness and loyaltyAuthority-sanctity. Overall, Clinton and Sanders's supporters showed relatively similar patterns valuing care and Fairness more than in-group, Authority, and Purity. Trump and Cruz supporters also showed relatively similar patterns valuing Fairness, in-group, Authority, and Purity more than care. In doing so, all of the candidates exemplified the usually favored dimensions of their respective Republican and Democratic political parties (Graham et al., 2009). 
Americans have grown increasingly divided along moral and political lines. Text analysis of tweets (short messages posted to Twitter, a popular social media website) has found evidence that shows that people who are high in the Purity foundation tend to create social networks comprised predominantly of other people who are also high on the Purity foundation (Dehghani, Johnson, Hoover, Sagi, \& Garten, et al., 2016).

The United States of America has become increasingly polarized and segregated in many ways, but particularly in terms of politics and morality. In terms of politics, numerous nationally representative surveys find that liberals and conservatives are endorsing ever-more extreme positions on cultural issues (Abramowitz, 2012). These divisions go far beyond simple disagreements over which policies are best. Americans actively avoid communicating with and openly discriminate against people with different political beliefs (Goldman \& Mutz, 2011; Munro, Lasane, \& Leary, 2010). This distance between political opponents can be observed in the media in the form of a separation of liberal and conservative Twitter users in the sharing of political tweets and increasing segregation of political blogs (Adamic \& Glance, 2005; Conover et al., 2011).

In addition to avoiding people who disagree with us, we actively seek out people that do agree with us. We consume media that supports and confirms our pre-existing beliefs (Stroud, 2008; Garrett, 2009; Iyengar \& Hahn, 2009). In other words, we like it when the media that we consume validates our thoughts, beliefs, and feelings. This bias towards consensual validation is exaggerated when people perceive threat, which campaigns sow when discussing the instability of the economy, the influx of undocumented immigrants, or the specter of terrorism (Greenberg et al., 1990; Pyszczynski et al., 1996; Vail, Arndt, Motyl, \& Pyszczynski, 2012). 
With recent technological innovations, it is easier than ever to do this. There has been an explosion of different news sources, catering to any specific audience (Mutz, 2006). We are becoming increasingly segregated in our media consumption, even within our political parties, gradually gathering into segregated clusters of people who agree on almost every issue, while completely disregarding the other side's arguments (Chopik \& Motyl, 2016; Frimer, Skitka, \& Motyl, under review; Motyl, 2014; Motyl, 2016; Motyl, Iyer, Oishi, Trawalter, \& Nosek, 2014). News media itself has become increasingly partisan, making it difficult to find a news source without some sort of political spin (Prior, 2013). This sort of behavior is not conducive to productive bipartisan discussion.

Consumption of highly polarized media may lead to stereotyping of the opposing party. Both liberals and conservatives display stereotypes about the other side's moral beliefs. While people can often predict the direction of Republican or Democrats' political beliefs, they often exaggerate the extremity of these beliefs, regardless of whether they are speaking about their own party or the other party (Graham, Nosek, \& Haidt, 2012). Stereotypes about the morality of the opposing party are likely associated with stereotypes about the moral worldviews of political candidates, and of the people that support them (Crawford, Modri, \& Motyl, 2013). Selective media consumption allows people to expose themselves to a single perspective, and may lead to negative stereotypes about other candidates and their supporters. For example, selective media consumption may be responsible for the stereotypes that Trump supporters are "crazy," or Sanders supporters are "ignorant kids" (Arceneaux, 2016; Nimmo, 2015).

Believing that the aforementioned data looking at the moral priorities of people who supported the different political candidates were limited, as they relied on the self-reported surveys of volunteers who volunteered to participate, we devised a study to conceptually 
replicate these findings using a more naturalistic methodology: actual speech on Twitter which has become a popular means of political communication among politically-engaged Americans. Twitter contains immense stores of accessible data that is ripe for textual analysis (Pak \& Paroubek, 2010). It allows researchers to collect data on events in real time as events unfold. In this case, Twitter provided a simple method for collecting data on many supporters of the main candidates running for their party's nomination near the ending of the primary election season.

As of June $13^{\text {th }}$, 2016, 2:21 PM CST, on Twitter, 9 million people followed Donald Trump's Twitter account, 6.9 million people followed Hillary Clinton, 1.3 million people followed Ted Cruz, and 2.1 million followed Bernie Sanders. To establish a comparison group, we also identified a non-political celebrity (John Stamos), who had a similar number of followers (1.9 million). For each of these five figures, we randomly selected 15,000-20,000 users who followed each of them and downloaded up to 200 of their most recent Tweets. This yielded a sample of 86,061 people who Tweeted 141,903,439 words. During data processing, we discovered that 124 of these people followed more than one of the figures. To allow for a clean comparison of followers of each of the candidates, we excluded these 124 people from all subsequent analyses. Our de-identified data can be accessed at osf.io/z4h97.

We conducted a form of text analysis that uses counts of key words and phrases to extract meaningful psychological constructs from large bodies of text (Tausczik \& Pennebaker, 2010). Text analysis of tweets can provide insight into who is talking about what, and how they are talking about it. Text analysis performed by Sylwester and Purver (2015) has shown several reliable differences in language uses between Democrats and Republicans. For example, Democrats tend to use more anxiety words, while Republicans tend to use more words related to achievement as opposed to more concrete plans. 
We used this data to test two competing hypotheses: The Party Line hypothesis and the Ideologue hypothesis.

The Party Line Hypothesis states that similarities and differences between candidates will fall roughly along party lines. Supporters of Clinton will be most similar to Sanders, and supporters of Cruz will be most similar to supporters of Trump and vice-versa. This difference should be particularly prevalent in terms of morality. Previous research has shown that liberals tend to place the most emphasis on the Harm/care and Fairness/cheating foundations of morality, and conservatives place similar emphasis on all five foundations (Graham et al., 2009). If this hypothesis is correct we would expect supporters to speak the most about moral foundations that are consistent with their political ideology. Clinton and Sanders supporters should look similar to each other, as should Cruz and Trump.

According to the Ideologue Hypothesis, supporters of the ideologue candidates (Cruz and Sanders) will be more similar to each other than Trump and Clinton supporters, and vice-versa. There is support for this hypothesis as well. People with more extreme political views, regardless of their side of the political spectrum, tend to act more similarly to each other than to moderates of their own party (Sidanius, 1984; van Prooijen, Krouwel, Boiten, \& Eendebak, 2015; Tetlock, 1983). If this is the case, we would expect Cruz and Sanders to use more party-consistent moral language than Trump and Clinton.

We used the Moral Foundations Dictionary for our analyses (Graham, Haidt, \& Nosek, 2009). The Moral Foundations Dictionary contains words coded to reflect the five Moral Foundations mentioned earlier: Care, Fairness, Loyalty, Authority, and Purity. The Moral Foundations Dictionary has been used in empirical work to yield results consistent with other methodologies. For example, liberal speakers tended to use words found in the Harm and 
Fairness sub-dictionaries of the Moral Foundations Dictionary, whereas conservative speakers tended to use words found in the Ingroup, Authority, and Purity sub-dictionaries (Graham et al., 2009). We would expect such a pattern of results given conservatives' increased reliance on Ingroup, Authority, and Purity compared to liberals, and liberals' increased reliance on Harm and Fairness compared to conservatives.

We used the Moral Foundations Dictionary's measure of general morality to determine which twitter users spoke about morality the most, and which spoke about it the least. This subdictionary uses words like "law", "principle", "piety", and "wrong" to measure how much people speak about morality more generally. Then we turned to the dictionary's foundations for a finergrain analysis of what types of morality followers were speaking about. The Moral Foundations Dictionary is split into two categories: "virtue" and "vice." The "virtue" sub dictionary contains words that correspond with the more positive end of the moral foundations spectrum: care, Fairness, loyalty, Authority, and Purity. However, for the purposes of our analysis, we chose to use the "vice" sub-dictionary. ${ }^{\text {ii }}$

The "vice" sub-dictionary is further separated into various sub dictionaries that contain words that correspond with the opposite end of the spectrum on the five moral foundations: Harm, cheating, betrayal, subversion, and degradation. The Harm sub-dictionary contains words like "abuse", "kill”, "damage", and "abandon" that measure the degree to which people acknowledge the violation of the Harm foundation in their everyday lives. The cheating subdictionary contains words like "bias", "unfair", "dishonest", and "exclude" to measure how often people speak about perceived violations of fair procedures or outcomes. The betrayal subdictionary contains words like "treason", "desert", "enemy", and "disloyal" to measure how often people exclude others from their in-group in their speech. The subversion sub-dictionary 
contains words like "defy", "unfaithful", "insubordinate", and "riot" to measure how frequently people signal the disobedience toward an Authority figure in their speech. The degradation subdictionary contains words like "wicked", "sin", "disgust", and "disease" to measure how sensitive people are to violations of both physical and spiritual integrity. Preliminary analyses.

All of the means presented below represent the average percentage of words related to that topic out of the total words tweeted per Twitter user. All means have been standardized and centered on the sample mean to make it easier to spot differences between groups. Due to our large sample size, the $p$-values of all of our omnibus tests are less than .001 , and will not be reported here.

The Moral Foundations Dictionary includes a measure of general moral language. There were not many differences between followers of the different candidates in general moral language. Our apolitical baseline used an amount of moral language that was approximately equal to the sample average. Sanders followers, Trump followers, and Cruz followers were all statistically indistinguishable from the baseline (all $p s>.15$ ). Clinton followers used less moral language than the baseline $(p=.04$, See Figure 1). 


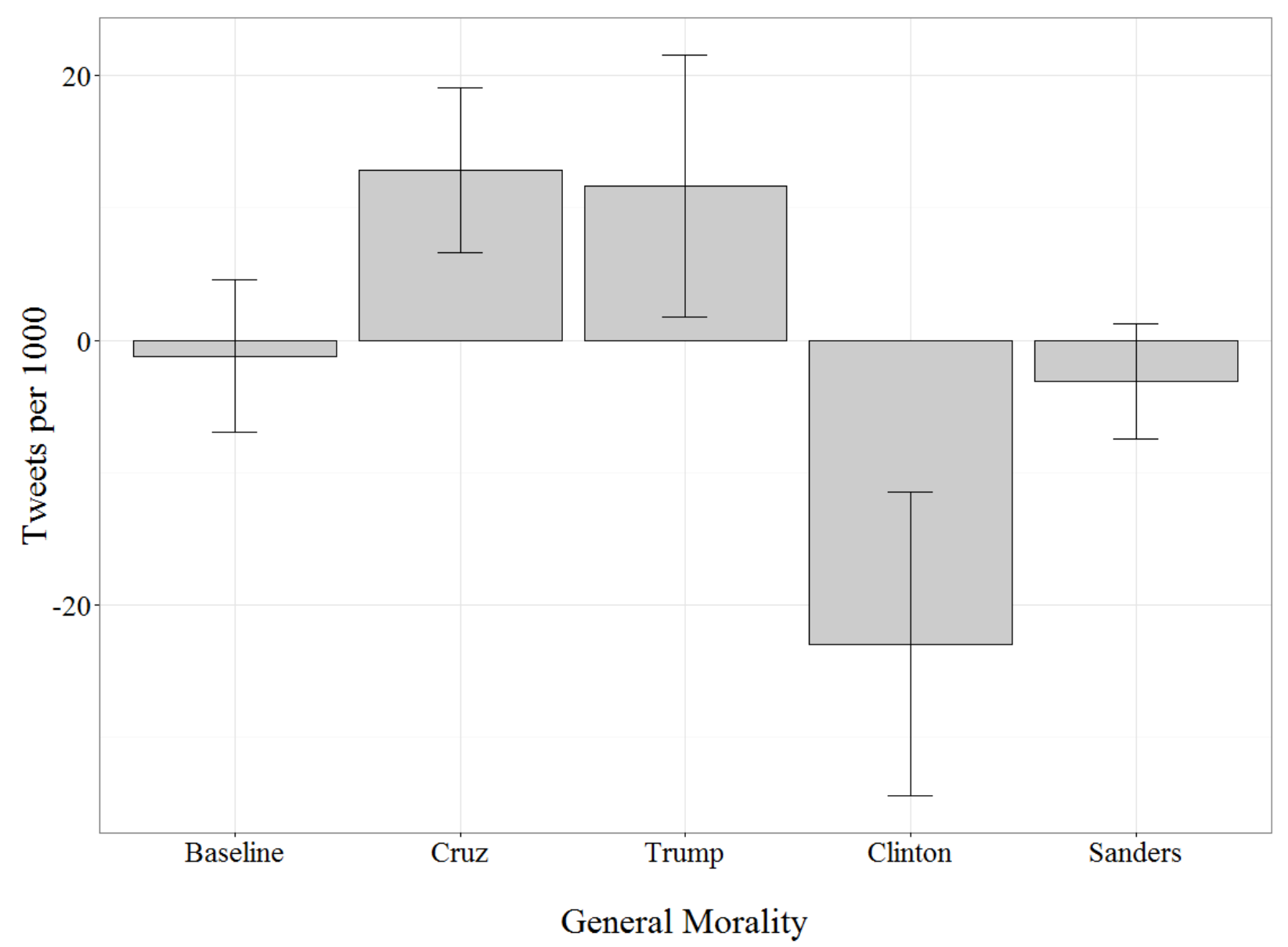

Figure 1. A representation of the means for the followers of each candidate for general moral language. "0" represents the mean for the total sample. Bars that fall below " 0 " are below average, and bars that fall above " 0 " are above average. Our baseline represents the mean for John Stamos' followers.

\section{Moral Foundations}

It appears that some candidates use slightly more moral language than others, but it remains unclear what the implications of speaking more about morality are in general. Pluralistic accounts of morality suggest that followers of these candidates may be similarly high in moral language, yet differ in their moral priorities (Graham, et al. 2012; Haslam \& Fiske, 1999; 
Shweder, Much, Mahapatra, \& Park, 1997). Therefore, we used the Moral Foundations

Dictionary to assess differences in the moral content of the tweets of the followers of these candidates.

Means and standard deviations for all foundations can be found in Table 1, and Cohen's $d$ s for pairwise comparisons can be found in Table 2 .

Harm/Care. Baseline participants speak about Harm less than followers of all of the political candidates included in the current study (all $p s<.001$ ). Based off of previous findings, we would expect that Trump followers would not be very concerned about this foundation compared to our baseline (e.g., Ekins \& Haidt, 2016). And, Trump followers do speak less about Harm than the average Twitter user in our sample, but more than our baseline $(p<.001)$. Clinton followers speak about it at approximately the same frequency as Trump's $(p=.07)$, and more than our baseline. Both Cruz and Sanders $(p=.24)$ followers speak the most about Harm.

Cheating/Fairness. Our baseline participants, as before, speak about cheating the least of all (all $p \mathrm{~s}<.001)$. Trump followers speak about cheating more than baseline users, but less than our average user. Clinton followers speak about it slightly more than Trump followers $(p=.03)$, while both Cruz and Sanders followers $(p=.66)$ speak about it more than Clinton followers (both $p$ s $<.001)$.

Betrayal/Loyalty. Baseline participants speak of betrayal the least (all $p \mathrm{~s}<.001$ ). Clinton followers speak about betrayal more than our baseline, but less than the sample average. Trump followers speak about betrayal more than our baseline, and slightly more than Clinton followers $(p=.02)$. Sanders followers speak about betrayal slightly more than Trump followers $(p=.002)$, and Cruz followers speak of it most of all $(p<.001)$. 
Subversion/Authority. Baseline participants speak about subversion of Authority the least (all $p$ s <.03). Clinton followers speak of it more than our baseline, but less than average. Trump followers speak of about the same amount as Clinton followers $(p=.16)$. Sanders followers speak about subversion more than Trump and Clinton's, and slightly above average (both $p$ s $<.02)$. Cruz followers spoke of it most of all $(p<.001)$.

Degradation/Purity. Baseline participants speak about Purity in an amount that was consistent with the sample mean. Trump and Clinton followers both speak about it less than average $(p=.43)$, and less than baseline followers (both $p \mathrm{~s}<.02)$. Cruz and Sanders followers both speak about it more than average $(p=.09)$. Cruz followers are not statistically different from baseline ( $p=.07$ ), but Sanders followers spoke about Purity significantly more than baseline followers $(p<.001)$.

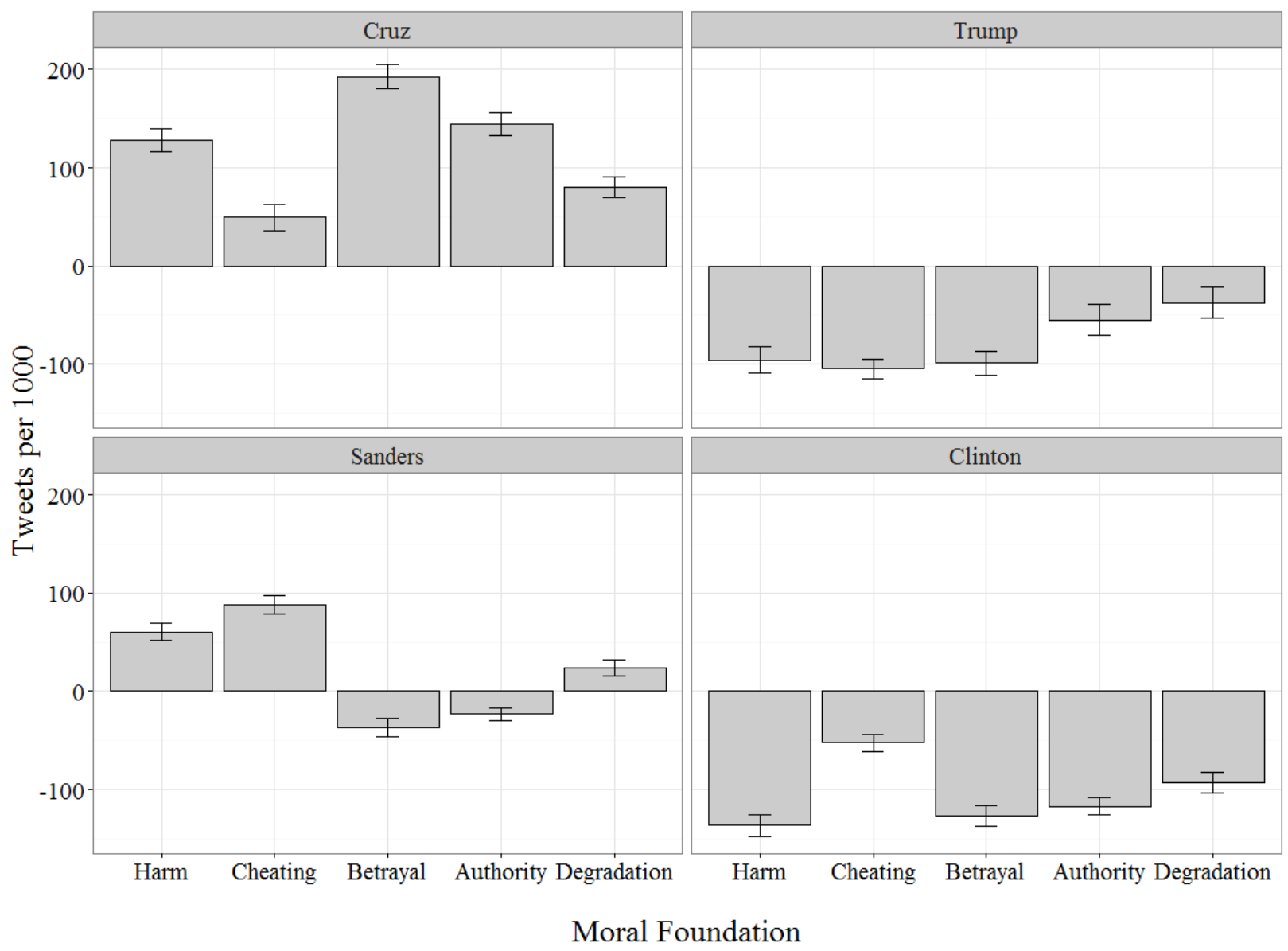


Figure 2. Means and standard errors for the followers of each candidate for their usage of Moral Foundations language. "0" represents the mean for the total sample. Our baseline is composed of the means for John Stamos followers.

Overall. Trump and Clinton followers show very similar patterns of diction. Both are below average on every foundation. Their more politically polarized counterparts, Cruz and Sanders followers, are above average on most foundations. In other words, followers of the less ideological candidates are more similar to each other than they are to their more extreme counterparts, and vice-versa (See Figure 2). Followers of the candidates are generally more likely to use words related to the five moral priorities than the people who follow our apolitical baseline, though this is not true of general speech about morality.

\section{Table 1}

Standardized descriptive statistics; all variables are centered on the sample mean

\begin{tabular}{llllll}
\hline & Baseline & Cruz & Trump & Clinton & Sanders \\
\hline General Morality & $0.00(0.79)$ & $0.02(1.24)$ & $-0.02(0.87)$ & $-0.03(1.15)$ & $0.04(0.85)$ \\
Harm & $-0.10(0.78)$ & $0.11(1.21)$ & $-0.04(1.09)$ & $-0.06(0.96)$ & $0.10(0.88)$ \\
Cheating & $-0.07(0.33)$ & $0.06(1.63)$ & $-0.02(0.86)$ & $0.0003(0.91)$ & $0.05(0.71)$ \\
Betrayal & $-0.12(0.46)$ & $0.19(1.44)$ & $-0.03(1.03)$ & $-0.05(0.79)$ & $0.01(1.00)$ \\
Subversion & $-0.06(0.7)$ & $0.11(1.51)$ & $-0.02(0.93)$ & $-0.04(0.85)$ & $0.008(0.62)$ \\
Degradation & $0.0001(0.79)$ & $0.02(1.24)$ & $-0.02(0.87)$ & $-0.03(1.15)$ & $0.04(0.85)$ \\
\hline
\end{tabular}




\section{Table 2}

Cohen's $d$ scores for all pairwise comparisons. Scores represent row minus column means, so that positive numbers mean that the followers of a candidate in the row scored higher than the followers of the candidate in the column.

\begin{tabular}{|c|c|c|c|c|}
\hline & Baseline & Cruz & Trump & Clinton \\
\hline \multicolumn{5}{|l|}{ General Morality } \\
\hline Cruz & 0.02 & - & e & . \\
\hline Trump & 0.01 & -0.001 & $\cdot$ & . \\
\hline Clinton & -0.02 & -0.03 & -0.03 & . \\
\hline Sanders & -0.002 & -0.02 & -0.02 & 0.02 \\
\hline \multicolumn{5}{|l|}{ Harm } \\
\hline Cruz & 0.20 & . & . & . \\
\hline Trump & -0.06 & -0.12 & . & . \\
\hline Clinton & -0.04 & -0.15 & -0.02 & . \\
\hline Sanders & 0.23 & -0.01 & 0.13 & 0.17 \\
\hline \multicolumn{5}{|l|}{ Cheating } \\
\hline Cruz & 0.11 & . & . & . \\
\hline Trump & 0.07 & -0.06 & . & . \\
\hline Clinton & 0.11 & -0.04 & 0.03 & . \\
\hline Sanders & 0.23 & -0.003 & 0.04 & 0.06 \\
\hline \multicolumn{5}{|l|}{ Betrayal } \\
\hline Cruz & 0.30 & . & - & . \\
\hline Trump & 0.13 & -0.17 & 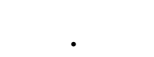 & . \\
\hline Clinton & 0.12 & -0.20 & -0.03 & . \\
\hline Sanders & 0.19 & -0.14 & 0.04 & 0.07 \\
\hline \multicolumn{5}{|l|}{ Subversion } \\
\hline Cruz & 0.15 & 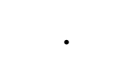 & . & . \\
\hline Trump & 0.05 & -0.10 & . & . \\
\hline Clinton & 0.03 & -0.12 & -0.02 & . \\
\hline Sanders & 0.10 & -0.08 & 0.04 & 0.06 \\
\hline \multicolumn{5}{|l|}{ Degradation } \\
\hline Cruz & 0.04 & . & . & . \\
\hline Trump & -0.03 & -0.04 & . & . \\
\hline Clinton & -0.04 & -0.04 & -0.009 & . \\
\hline Sanders & 0.04 & 0.02 & 0.07 & 0.07 \\
\hline
\end{tabular}




\section{Conclusion}

The common perception of Trump supporters is that they are extreme or even 'radical' in comparison to supporters of other candidates (Tesfaye, 2016; Tashman, 2016). Yet, previous analysis of their preferences in terms of different aspects of morality paint them as relatively similar to Ted Cruz's supporters (Ekins \& Haidt 2016).

Our data suggest otherwise. In terms of morality, Trump followers were not outliers. In fact, they rarely stood out on any of the dimensions that we measured. Overall, their moral language was very similar to Clinton followers. Trump and Clinton followers used less morallycharged language over all, and tended to be low on emotional and trait terms, with some variation on Trump's part.

In terms of morality, our data support the Ideologue hypothesis, and provide little evidence for the Party Line Hypothesis. A candidate's adherence to their party's values is a more reliable predictor for their follower's speech patterns than their political ideology alone. Followers of less ideological candidates, like Trump and Clinton, use less moral language, while followers of ideologues like Cruz and Sanders use more moral language. Their patterns of moral speech are roughly similar to those observed in other studies of liberals and conservatives (Graham et al., 2009). As expected people who follow a liberal ideologue, like Sanders, write relatively more about care/Harm and Fairness/cheating. People who follow a conservative ideologue, like Cruz, write relatively evenly on care/Harm, loyalty/betrayal, and Authority/subversion, though they write relatively less about Fairness/cheating and Purity/degradation, which deviates somewhat from the usual pattern. This may be because our sample rarely talked about Purity/degradation overall. It is possible that any differences were masked by conversational norms on Twitter. 
In short, the data provide evidence for both parts of the Ideologue Hypothesis: followers of the less ideological candidates, Trump and Clinton, tweeted more similarly, and followers of the more ideological candidates, Cruz and Sanders, tweeted more similarly and in more morally polarized ways.

Our analyses do have their strengths and weaknesses. Our sample is large, and it relies on real behavior as opposed to survey responses, which may be subject to a variety of response biases. However, the effect sizes are small, and we do not know much about these users. We cannot guarantee that there is a perfect correlation between candidates' followers on Twitter and their supporters. Trump was a celebrity long before he was a politician, and many of his Twitter followers may have followed him long before he decided to run for president. But there is evidence that it is possible to reliably estimate Twitter users' ideology based upon the people that they follow, so it seems likely that many of them do support him (Barberá et al., 2015). More than that, the diction of his followers resembles that of Clinton followers considerably more than it resembles John Stamos followers. But John Stamos is just one celebrity. His followers may not be representative of the general population. Further research using multiple control people will be necessary for a more accurate baseline. It is also possible that followers become less morally polarized when their candidates win than when they lose, but again, further research is required to speak to this point.

For the time being, it appears that the majority of Trump's followers are not as radical as the media suggests (Tesfaye, 2016; Tashman, 2016). Their moral values are more in line with Clinton followers. Trump was a Democrat who is now running as a Republican, and Clinton worked for Republican groups in the past, and is now running as a Democrat. This sets them apart from ideologues like Cruz and Sanders who have remained on their sides of the aisle for 
the duration of their political careers. The people who support ideologues like Cruz and Sanders are the ones using extreme moral language, and they are more likely to show party-line differences in the moral foundations than people who support non-ideologues like Trump and Clinton. In short, followers of ideologues are more morally polarized than followers of the Democratic and Republican presidential nominees. What this study shows is that if either Trump or Clinton succeed to the presidency they may prove themselves to be more pragmatic than Sanders or Cruz might have been, and, importantly, their followers are more likely to permit them some considerable flexibility in their actual policy making than they might have permitted the more ideologically driven Cruz or Sanders. 


\section{References}

Adamic, L. A., \& Glance, N. (2005, August). The political blogosphere and the 2004 US election: divided they blog. Paper presented at the 3rd international workshop on Link discovery.

Arceneaux, M. (2016, January 14). Here are the levels of crazy Donald Trump supporters have reached. VH1. Retrieved from http://www.vh1.com/news/236293/crazy-donald-trump-supporters

Barberá, P., Jost, J. T., Nagler, J., Tucker, J. A., \& Bonneau, R. (2015). Tweeting from left to right: Is online political communication more than an echo chamber?. Psychological science, 26(10), 1531-1542.

Chopik, W. J., \& Motyl, M. (2016). Ideological Fit Enhances Interpersonal Orientations. Social Psychological and Personality Science.

Conover, M., Ratkiewicz, J., Francisco, M. R., Gonçalves, B., Menczer, F., \& Flammini, A. (2011). Political polarization on twitter. Presented at the fifth international conference on weblogs and social media.

Crawford, J. T., Modri, S. A., \& Motyl, M. (2013). Bleeding-Heart Liberals and Hard-Hearted Conservatives: Subtle Political Dehumanization Through Differential Attributions of Human Nature and Human Uniqueness Traits. Journal of Social and Political Psychology, 1(1), 86-104.

Dehghani, M., Johnson, K., Hoover, J., Sagi, E., Garten, J., Parmar, N. J., ... \& Graham, J. (2016). Purity homophily in social networks. Journal of Experimental Psychology: General, 145(3), 366-375.

Diamond, J. (2016, April 1). Abortion and 10 other Donald Trump flip-flops. CNN. Retrieved from http://www.cnn.com/2016/03/31/politics/donald-trump-positions-flip-flops/

Donald Trump. (2016, July 4). OnTheIssues. Retrieved from http://www.ontheissues.org/Donald_Trump.htm 
Donald Trump Biography. (2016, July 4). Biography.com. Retrieved from http://www.biography.com/people/donald-trump-9511238

Ekins, J. \& Haidt, J. (2016, February 5). Donald Trump supporters think about morality differently than other voters. Here's how. Vox.com. Retrieved from http://www.vox.com/2016/2/5/10918164/donald-trump-morality

Emery, C. (2016, January 20). Spot check of Hillary Clinton's senate record fails to support bipartisanship claim. Politifact.com. Retrieved from http://www.politifact.com/truth-ometer/statements/2016/jan/20/hillary-clinton/spot-check-hillary-clintons-senate-record-immolate/

Enten, H. (2015, April 30). Enter the Democratic primary's liberal alternative: Bernie Sanders!.

FiveThirtyEight. Retrieved from http://fivethirtyeight.com/features/bernie-sanders-presidentannouncement-liberal-alternative-2016-democratic-primary/

Flegenheimer, M. (2016, April 17). Ted Cruz’s conservatism: The pendulum swings consistently Right. The New York Times. Retrieved from http://www.nytimes.com/2016/04/18/us/politics/ted-cruzconservative.html

Florida Exit Polls. (2016, March 15). The New York Times. Retrieved from Ohio Exit Polls (2016, March 15). The New York Times. Retrieved from http://www.nytimes.com/interactive/2016/03/15/us/elections/ohio-republican-poll.html?_r=0

Frimer, J., Skitka, L. J., \& Motyl, M. (under review). Liberals and Conservatives are Similarly Motivated to Remain Ignorant of One Another's Opinions.

Garrett, R. K. (2009). Echo chambers online?: Politically motivated selective exposure among Internet news users1. Journal of Computer Mediated Communication, 14(2), 265-285.

Goldman, S. K., \& Mutz, D. C. (2011). The friendly media phenomenon: A cross-national analysis of cross-cutting exposure. Political Communication, 28(1), 42-66. 
Graham, J., Haidt, J., \& Nosek, B. A. (2009). Liberals and conservatives rely on different sets of moral foundations. Journal of Personality and Social Psychology, 96(5), 1029-1046.

Graham, J., Nosek, B. A., \& Haidt, J. (2012). The moral stereotypes of liberals and conservatives: Exaggeration of differences across the political spectrum. PloS one, 7(12), e50092.

Graham, J., Haidt, J., Koleva, S., Motyl, M., Iyer, R., Wojcik, S., \& Ditto, P. H. (2013). Moral foundations theory: The pragmatic validity of moral pluralism. Advances in Experimental Social Psychology, 47, 55-130.

Greenberg, J., Pyszczynski, T., Solomon, S., Rosenblatt, A., Veeder, M., Kirkland, S., \& Lyon, D. (1990). Evidence for terror management theory II: The effects of mortality salience on reactions to those who threaten or bolster the cultural worldview. Journal of personality and social psychology, 58(2), 308.

Haidt, J., \& Graham, J. (2007). When morality opposes justice: Conservatives have moral intuitions that liberals may not recognize. Social Justice Research, 20(1), 98-116.

Haslam, N., \& Fiske, A. P. (1999). Relational models theory: A confirmatory factor analysis. Personal Relationships, 6(2), 241-250.

Horowitz, J. (2016, March 25). Bernie Sanders consistent over decades in his call for 'revolution.' The New York Times. Retrieved from http://www.nytimes.com/2016/03/26/us/politics/bernie-sanders-

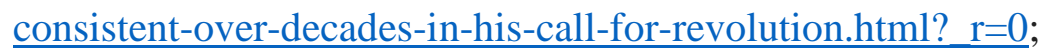

Hunter, J. D. (1992). Culture wars: The struggle to control the family, art, education, law, and politics in America. Basic Books.

Iyengar, S., \& Hahn, K. S. (2009). Red media, blue media: Evidence of ideological selectivity in media use. Journal of Communication, 59(1), 19-39. 
Johnson, K. M., Iyer, R., Wojcik, S. P., Vaisey, S., Miles, A., Chu, V., \& Graham, J. (2014, December 11). Ideology - Specific Patterns of Moral Indifference Predict Intentions Not to Vote. Analyses of Social Issues and Public Policy, 14(1), 61-77.

Keith, T. (2015) Bernie Sanders has stuck to the same message for 40 years. NPR. Retrieved from http://www.npr.org/2015/12/11/459231940/bernie-sanders-has-stuck-to-the-same-message-for$\underline{40-\text { years }}$

Keneally, M. (2016, June 16). One year of Donald Trump's campaign: Times he's flip-flopped. $A B C$ News. Retrieved from http://abcnews.go.com/Politics/history-donald-trumps-flip-floppingissues-presidential-campaign/story?id=39063811

Li, D. (2016, April 5). Here's why people are voting for Trump. New York Post. Retrieved from http://nypost.com/2016/04/05/heres-why-people-are-voting-for-trump/

Martindale, C. (2008). Regressive imagery dictionary. RID-pt. ykd.

Moody, C. (2015, July 22). Trump in '04: 'I probably identify more as Democrat.' CNN. Retrieved from http://www.cnn.com/2015/07/21/politics/donald-trump-election-democrat/

Motyl, M. (2014). "If he wins, I'm moving to Canada": Ideological migration threats following the 2012 U.S. Presidential election. Analyses of Social Issues and Public Policy.

Motyl, M. (2016). Liberals and conservatives are geographically dividing. In P. Valdesolo \& J. Graham (Eds.), Social Psychology of Political Polarization. Psychology Press.

Motyl, M., Iyer, R., Oishi, S., Trawalter, S., \& Nosek, B. A. (2014). How ideological migration geographically segregates groups. Journal of Experimental Social Psychology, 51, 1-14.

Munro, G. D., Lasane, T. P., \& Leary, S. P. (2010). Political partisan prejudice: Selective distortion and weighting of evaluative categories in college admissions applications. Journal of Applied Social Psychology, 40(9), 2434-2462. 
Mutz, D. C. (2006). How the mass media divide us. Red and Blue Nation? Characteristics and Causes of America's Polarized Politics, Washington D.C.: Brookings Institution Press.

Which presidential candidates are winning the money race?. (2016, June 22). The New York Times.

New Hampshire Exit Poll. (2016, February 9). The New York Times. Retrieved from http://www.nytimes.com/interactive/2016/02/09/us/elections/new-hampshire-republicanpoll.html

Nimmo, K. (2015, November 10). Socialism? Young Bernie Sanders supporters are clueless. Info Wars. Retrieved from http://www.infowars.com/socialism-young-bernie-sanders-supporters-areclueless/

Ohio Exit Polls (2016, March 15). The New York Times. Retrieved from http://www.nytimes.com/interactive/2016/03/15/us/elections/ohio-republican-poll.html?_r=0

Ostroy, A. (2015, November 19). Here's how/why Jeb Bush will win the GOP nomination. The Huffington Post. Retrieved from http://www.huffingtonpost.com/andy-ostroy/heres-howwhy-jebbush-will-win-the-gop-nomination_b_8598894.html

Pak, A., \& Paroubek, P. (2010, May). Twitter as a Corpus for Sentiment Analysis and Opinion Mining. Paper presented at the International conference on language resources and evaluation.

Prior, M. (2013). Media and Political Polarization. Annual Review of Political Science, 16: 101-27.

Pyszczynski, T., Wicklund, R. A., Floresku, S., Koch, H., Gauch, G., Solomon, S., \& Greenberg, J. (1996). Whistling in the dark: Exaggerated consensus estimates in response to incidental reminders of mortality. Psychological Science, 7(6), 332-336.

Riddel, K. (2015, October 12). Hillary Clinton flip-flops from 2008 in bid for liberal voters' support. The Washington Times. Retrieved from: 
http://www.washingtontimes.com/news/2015/oct/12/hillary-clinton-flip-flops-from-2008-

positions-in-/

Rifkin, J. (2015, December 30). The worst political predictions of 2015. Politico Magazine. Retrieved from http://www.politico.com/magazine/story/2015/12/the-worst-political-predictions-of-2015$\underline{213484}$

Sen. Bernie Sanders. (2016, July 5). Govtrack.us. Retrieved from https://www.govtrack.us/congress/members/bernard_sanders/400357

Sen. Ted Cruz. (2016, July 5). Govtrack.us. Retrieved from https://www.govtrack.us/congress/members/ted_cruz/412573

Shweder, R., Much, N., Mahapatra, M., \& Park, L. (1997). Divinity and the "Big Three" Explanations of Suffering. Morality and Health, 119, 119-169.

Sidanius, J. (1984). Political interest, political information search, and ideological homogeneity as a function of sociopolitical ideology: A tale of three theories. Human Relations, 37(10), 811-828.

Sides, J. \& Tesler, M. (2016, March 2). How political science helps explain the rise of Trump: Most voters aren't ideologues. The Washington Post. Retrieved from https://www.washingtonpost.com/news/monkey-cage/wp/2016/03/02/how-political-sciencehelps-explain-the-rise-of-trump-most-voters-arent-ideologues/

Silver, N. (2015a, August 11). Donald Trump is winning the polls- And losing the nomination. FiveThirtyEight. Retrieved from http://fivethirtyeight.com/datalab/donald-trump-is-winning-thepolls-and-losing-the-nomination/

Silver, N. (2015b, April 12). Clinton begins the 2016 campaign, and it's a toss-up. FiveThirtyEight. Retrieved from http://fivethirtyeight.com/features/clinton-begins-the-2016-campaign-and-its-atoss-up/ 
Sowell, T. (2007). A conflict of visions: Ideological origins of political struggles. Basic Books.

Steinhauer, J. (2016, January 1). Republican says 'malleable' Donald Trump is more electable than a 'rigid' Ted Cruz. The New York Times. Retrieved from http://www.nytimes.com/politics/firstdraft/2016/01/26/republican-says-malleable-donald-trump-is-more-electable-than-a-rigid-ted$\underline{\text { cruz/? } \mathrm{r}=0}$

Sylwester, K., \& Purver, M. (2015). Twitter language use reflects psychological differences between Democrats and Republicans. PloS one, 10(9), e0137422.

Tashman, B. (2016, May 9). Trump's Team: The bigoted, unhinged conspiracy theorists benefiting from Donald Trump's campaign. Right Wing Watch. Retrieved from http://www.rightwingwatch.org/content/trumps-team-bigoted-unhinged-conspiracy-theoristsbenefiting-donald-trumps-campaign

Tausczik, Y. R., \& Pennebaker, J. W. (2010). The psychological meaning of words: LIWC and computerized text analysis methods. Journal of Language and Social Psychology, 29(1), 24-54.

Tesfaye, S. (2016, February 16). Donald Trump's South Caroline supporters are the most radical yet. Salon. Retrieved from http://www.salon.com/2016/02/16/donald_trumps_south_carolina_supporters_are_the_most_radi $\underline{\text { cal_yet/ }}$

Tetlock, P. E. (1983). Cognitive style and political ideology. Journal of Personality and Social Psychology, 45(1), 118-126.

Vail, K. E., Arndt, J., Motyl, M., \& Pyszczynski, T. (2012). The aftermath of destruction: Images of destroyed buildings increase support for war, dogmatism, and death thought accessibility. Journal of Experimental Social Psychology, 48(5), 1069-1081. 
van Prooijen, J. W., Krouwel, A. P., Boiten, M., \& Eendebak, L. (2015). Fear Among the Extremes How Political Ideology Predicts Negative Emotions and Outgroup Derogation. Personality and Social Psychology Bulletin, 0146167215569706.

\footnotetext{
${ }^{i}$ Discussions on the YourMorals.org blog suggest that there may be a $6^{\text {th }}$ foundation pertaining to liberty/oppression, but no peer-reviewed research has yet verified this possible foundation.

i" Additional analyses using the "virtue" sub-dictionary generally replicate the findings reported in this chapter using the "vice" sub-dictionary. We also conducted exploratory analyses on several emotion and trait variables from the Regressive Image Dictionary (Martindale, 2008). Summaries of all analyses can be accessed at osf.io/z4h97.
} 